\title{
Methodology for linking business processes undertaken during bridge load testing with the specification of required information according to OpenBIM standards
}

\author{
Tomasz Owerko ${ }^{1,}{ }^{*}$, Piotr Owerko ${ }^{2}$ \\ ${ }^{1}$ Department of Engineering Surveying and Civil Engineering, AGH University of Science and \\ Technology, Poland (PhD, Eng., DSc) \\ ${ }^{2}$ Faculty of Materials, Civil and Environmental Engineering, University of Bielsko-Biala (PhD Eng.)
}

\begin{abstract}
Correct process modelling is crucial for the implementation of BIM technology. Considering the interest of public procurement, the use of open standards supports the transparency of spending public money on construction projects. The aim of this paper is to model the flow of information at the stage of bridge load testing in order to properly use BIM technology for bridges. The authors present a concept known from software engineering - design pattern - a general, reusable solution for a commonly occurring problem within a given context, this time applied in infrastructure design.
\end{abstract}

\section{Introduction}

One of the main reasons behind applying BIM technology in the construction industry is to create and use coordinated, consistent and computable information about an engineering project during the design, construction as well as operation and management phase. In many countries, including Poland, after a bridge is built it has to be subjected to a load test in order to be accepted for use. A bridge load test is a well described procedure from a purely technical point of view, yet it has no good representation in information delivery manuals, for instance those described in ISO 29418 [1, 2]. Since the use of BIM in the project phase for infrastructure objects such as bridges will be standard in the next few years (a building SMART IFC Bridge Standard is under advanced construction), it is also important to be able to deliver and exchange proper information for a newly built bridge when it is tested and hopefully accepted for service. Taking full advantage of BIM technology would include an exchange of BIM information such as model view data for IFC-based data exchange [3]. Naturally, such a demand for an information process has to be well described in the Employers Information Requirements and has to have its representation in the BIM Execution Plan [4]. Correctly defined IDM (Information Delivery Manual) is a tool which helps to get full benefit of BIM. A properly applied BIM

\footnotetext{
*Corresponding author: owerko@agh.edu.pl
} 
would support management, operations and maintenance. In order to do so, data flow between parties has to be designed using process maps $[5,6]$.

The main objective of this paper is to analyse standard information requirements during the load test process, make proper identification of the actors included and propose a standard process map with the use of Business Process Modelling Notation (BPMN). This approach will help set the boundary for the extent of information contained within the process, establish the activities within the process, and show a logical sequence of the activities. The implementation of infrastructure investments, in particular the construction of bridge objects, should be related to the expectations of stakeholders. Their requirements are usually defined in documents called Organizational Information Requirements (OIR). They provide information input with an assumption that other sources can also exist to define the Project Information Requirements (PIR). On the other hand, OIR is a single source to contractual requirements generated as the Asset Information Requirements (AIR). One of the main BIM contract documents for the construction of bridges is the Exchange Information Requirements (EIR, also known as Employer's Information Requirements according to [7]). Its content is built from AIR as well as PIR. Asset Information Requirements determine the content, structure and methodology of the Asset Information Model in a very similar way like EIR determines the shape of the Project Information Model (PIM). Looking from an information hierarchy point of view both Asset and Project Information Models are deliverables in the BIM process.

BIM can be understood as a collaborative process which involves different stakeholders in the management of the assets and the exchange of models with structured data through the entire lifespan [8]. To support correct workflow, Information System (IS) has to be established with the database of the project where product data can be stored and retrieved throughout the cycle of the project [9]. In long term, from a public investor perspective the primary goal is to establish the state of interoperability defined as the exchange of information between multiple parties that use different software vendors without the loss of information [10].

\section{Methods}

Since there is no common benchmarking for companies that are applying BIM in bridge construction as described in EIR, process maps should assume some level of BIM maturity. There are several tools which have been developed for this purpose [11]. They are well described and tested. They have been used in the marketplace by consultants for several years. Rizal and Berlo [12] developed a method based on the previously known quick scan methodology supporting the objective assessment of the advancement of BIM technology implementation and the identification of areas for which BIM would bring most benefits to a given company. In the analogical work [13], five metrics have been identified which in a complementary way allow for the assessment of the effectiveness of the implementation of BIM technology.

In an ideal case, the BIM maturity level of the public customer and the build-and-design company is unified so the exchange of information may take place in accordance with the Information Delivery Manual (IDM). Within IDM, there are two perspectives. One of them is user requirements and the second are technical solutions. According to $[1,2]$ within the user requirements perspective the components of IDM can be described as:

- interaction maps, describing the roles and interactions between them,

- process maps, describing the overall process in which information exchange occurs,

- information delivery, describing information exchange needs,

- reference processes (stored exchange descriptions),

- project schedule (occurrences of processes in the context of a project). 
Interaction maps help to describe interfaces between the roles while hiding the complexity of the process within the domain of the roles as well as hiding the details of the interaction between the roles. From the user point of view, the use of abstract roles makes the interaction map valid for many different situations, just like design patterns can be used in many different scenarios in software engineering. The interaction map is a valuable tool for analyzing and defining the essential elements of a business process. In the described aspect of bridge test loading, several actors can be identified, namely:

- general contractor (construction manager),

- bridge designer (in the described scenario assumed to be a part of a general contractor team),

- investor (in the construction phase represented by a supervision inspector and a main contract engineer; in the maintenance stage represented by a facility manager),

- load testing laboratory (LTL design team and designer of load tests, LTL field team, LTL manager),

- designer and contractor of structural health monitoring (SHM) system (only on selected objects).

Since the standard notation used for business modelling does not support transaction it will be described in accordance with [14]. In our case a transaction will be a unit of work performed within a database management system - the BIM IT system (or similar system) against a database, and treated in a coherent and reliable way independent of other transactions. A transaction generally represents any change of information between the actors in the project. Just like in database engineering (part of computer science) we recommend the transaction to be, by definition, atomic, consistent, isolated and durable. Several transactions can be identified in a bridge load testing scenario (Table 1).

Table 1. Transaction table of bridge load testing.

\begin{tabular}{|c|c|}
\hline Transaction result & Transaction type \\
\hline $\begin{array}{c}\text { General contractor and then } \\
\text { investor, receives final results } \\
\text { of load testing (decision } \\
\text { whether to accept the object for } \\
\text { service, can be made) }\end{array}$ & $\begin{array}{c}\mathrm{T}_{1}: \\
\text { Delivery of the final results } \\
\text { of load testing (static and } \\
\text { dynamic) }\end{array}$ \\
\hline $\begin{array}{c}\text { General contractor receives the } \\
\text { design and prepares the object } \\
\text { for tests }\end{array}$ & $\begin{array}{c}\mathrm{T}_{2}: \\
\text { Delivery of load test design. }\end{array}$ \\
\hline $\begin{array}{c}\text { General contractor receives the } \\
\text { report (increasing knowledge } \\
\text { about the construction response } \\
\text { on e.g. stiffness criterion) }\end{array}$ & $\begin{array}{c}\mathrm{T}_{3}: \\
\text { Delivery of a brief report } \\
\text { with results of static load } \\
\text { testing. }\end{array}$ \\
\hline
\end{tabular}

An interaction map which represents the information flow during bridge load testing is shown in Fig. 1. Note that the scope of interaction contains all of transactions made by the Design-and-build company with its subcontractors needed to fulfill the final transaction to the public customer. 


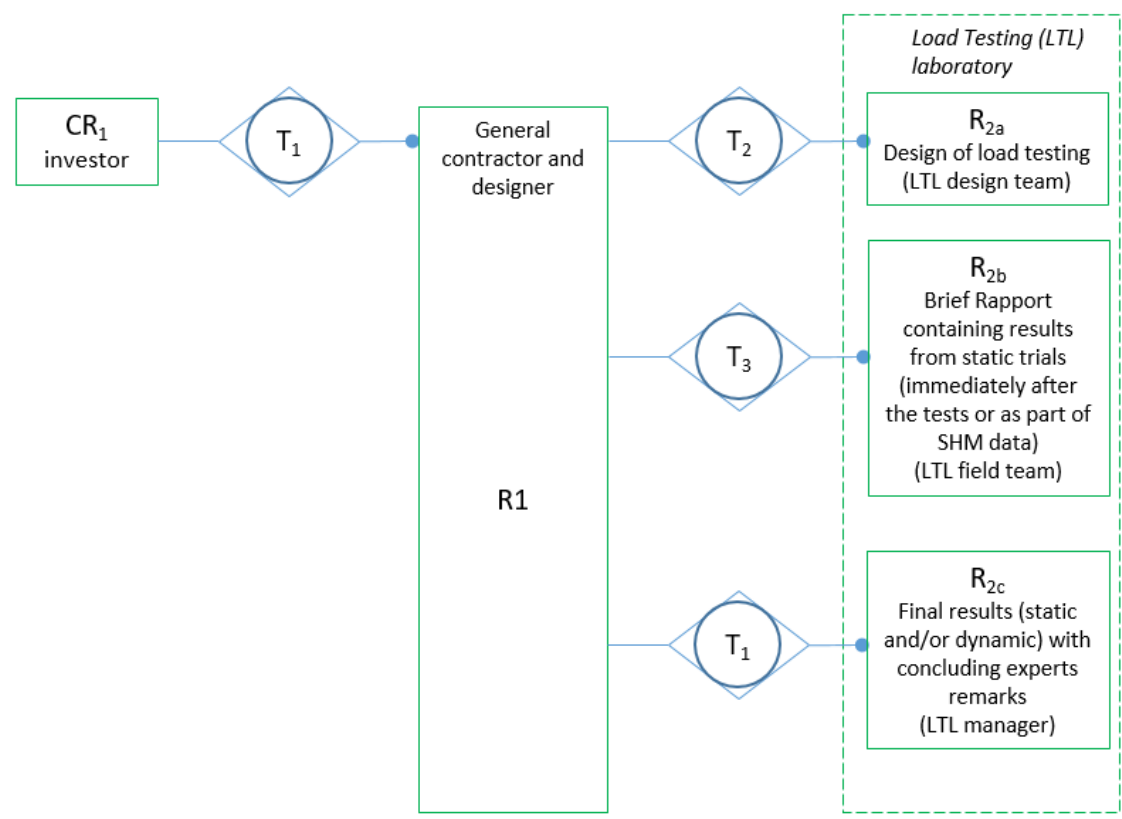

Fig. 1. Exemplary interaction map for a transaction identified for current recommendations and practise of performing load tests in Poland.

If the set of transactions is well identified it is possible to define a set of messages required for a particular purpose. It is useful to define them in one of the diagrams using Unified Modeling Language (UML) notation. Each of these sequence diagrams represents one transaction (Fig. 2-4)

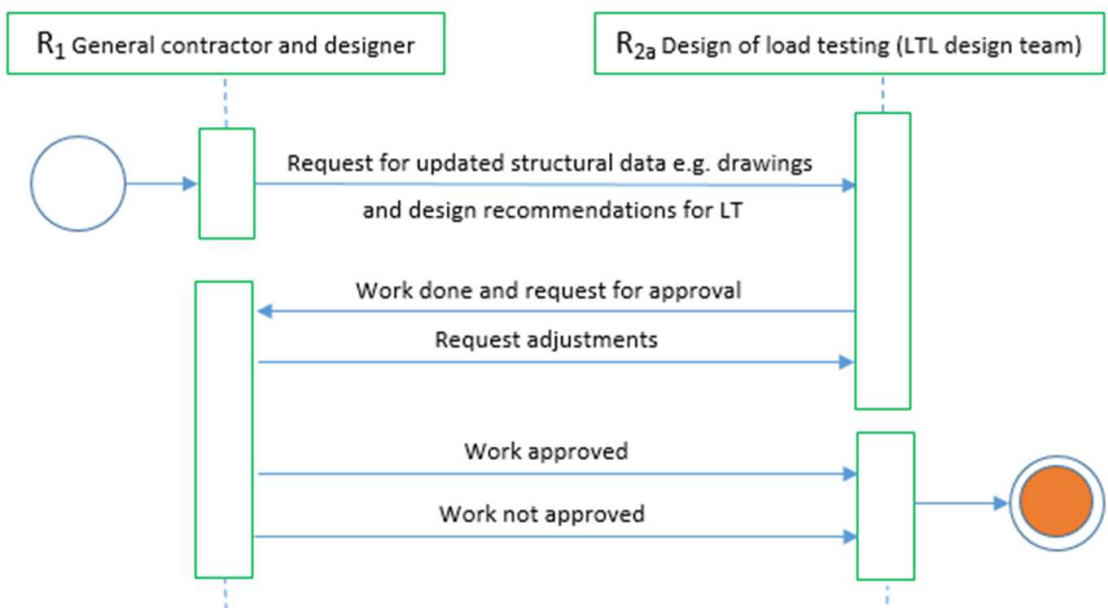

Fig. 2. Exemplary scenario of transaction $\mathrm{T} 2$ identified for current recommendations and practise of performing load tests in Poland.

Since every message contains data it is possible to identify the exchange requirements as well as the type and format that support it. As can be seen, transactions support the information process needed to define how a result is obtained by executing a role. Special concern should be made to ensure that agreed communication protocols are in place in order to ensure that the bridge load testing goals are achieved. 
On the other hand, process maps show the logical sequence of activities. We used BPMN notation to represent it. In the case of bridge load testing, seven actors can be identified, yet several of them can be aggregated as a composite role type. Each of the actors has its own pool and exchanges information with other parties. We identified four phases of the bridge load testing process:

- preliminary and final design phase (among other things, the preparation of the technical specification with the prerequisites for conducting construction works and the design of loading tests prior to opening),

- construction phase (in this phase the design of load testing is also prepared and consulted with the bridge designer and sometimes with the supervision inspector),

- phase of final acceptance of construction works and acceptance of the bridge for service (this phase includes in-situ load testing).

Since the actors, their lines, the process phases and data flow are well established, it is possible to draw a correct process map [15-17]. Note that both the process map and the interaction map are complementary to each other (Fig. 3. Messages in transaction).

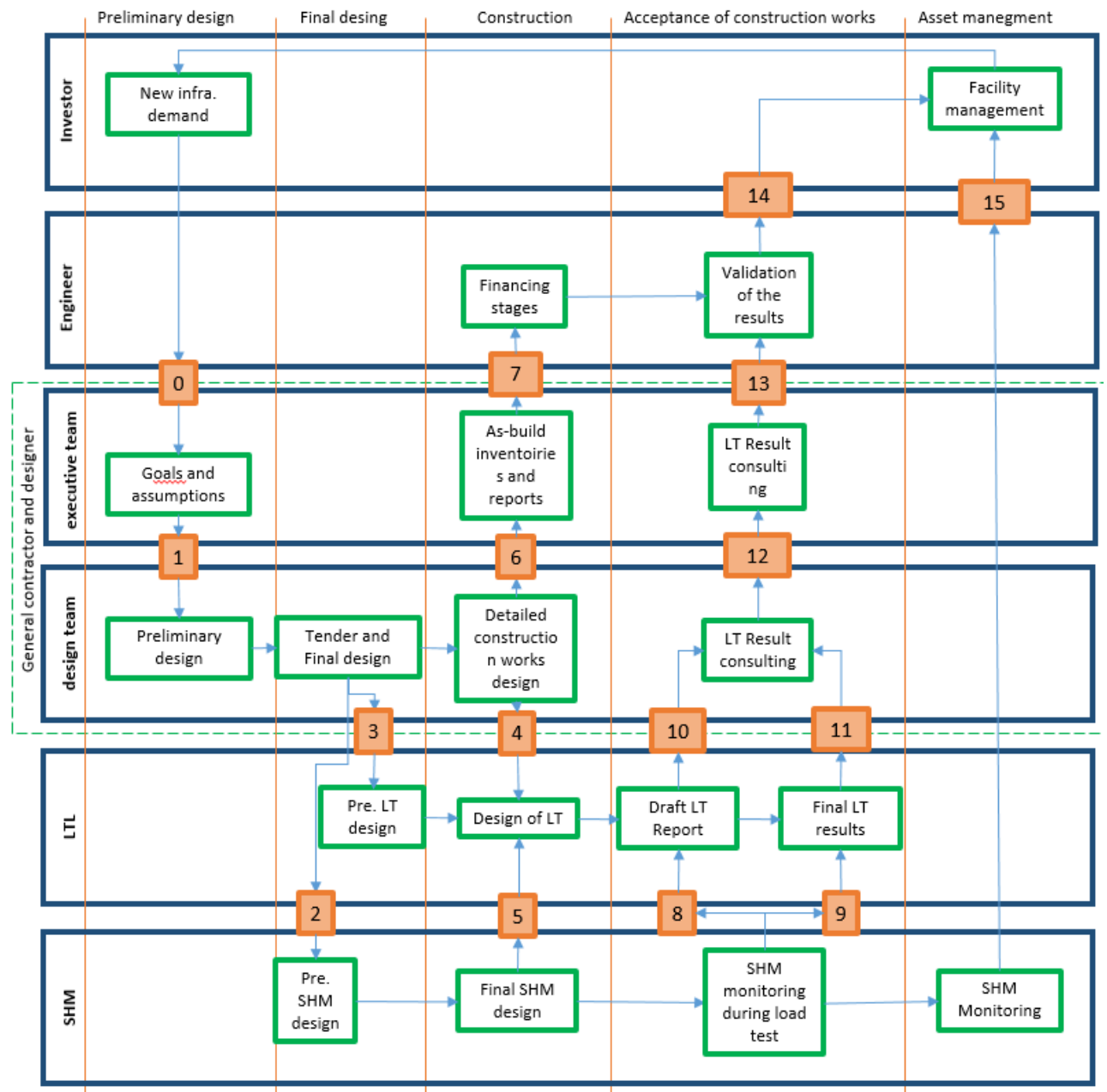

Fig. 3. Messages in transaction. 


\section{Design Pattern - definition and important remarks}

Generally, in software engineering a software design pattern was invented as a general, reusable solution to a commonly occurring problem within a given context in the (software) design. It is important to note that design patterns are not finished designs which can be directly implemented into a source or machine code - for instance they are not complete sets of UML diagrams supporting forward engineering systems. Instead they are rather templates which give a good idea on how to solve a problem and so can be used in many different situations. Design patterns can be understood as formalized best practices that the engineer can use to solve common problems. We will focus on some creational design patterns, structural design patterns as well as behaviour design patterns.

Before we can establish and implement BIM design patterns, we should try to use the existing ones since BIM heavily inheritance from software engineering. Our goal is to use good common practice and reuse proper BIM data flow in the next projects. We will try to identify which design patterns can by applied to the BIM process during construction and load testing of bridges.

Since well-defined design patterns have a quite rich documentation we can use them to accomplish some stages of the BIM data flow process. The examples used are only specific contexts of the bridge load testing and construction process, usually not directly related to each other.

To describe the relationship between the public customer and the design \& construction company during the construction project and the executive as well as construction phase we can try to use the Builder pattern. The exact course of the process is as follows: the Builder Pattern [18] consists of a Builder, ConcreteBuilder, Director and Product. The Director object is responsible for the construction process of a complex object but delegates the actual creation and assembly to the Builder interface. The Builder object specifies the interface for creating parts of the complex object. The Product represents the complex object that is created by the ConcreteBuilder objects. The Product consists of multiple parts that are created separately by the ConcreteBuilder objects. The ConcreteBuilder objects create and assemble the parts that make up the Product through the Builder interface.

Unique responsibilities (important assumption) in the construction process, especially in lean management technology, can be implemented according to the Singleton pattern. The basic advantage of its application is the implementation of the instance in accordance with the principle of lazy allocation and initialization - the object is appointed when it is necessary so the consumption of resources is limited - it is valid for time, space and money.

Since there are at least several properties of bridge object that should be monitored during the construction phase as well as the bridge load testing phase, the information flow in a BIM system can be supported by the Observer pattern. It suits near real-time data driven monitoring components very well - it is mainly used to implement distributed event handling systems. Both the bridge load testing software and SHM software should be implemented using this pattern.

If the design of strategy for the bridge load testing procedure is made by a global solution it has to be flexible to meet the rudiments of different types of bridges. Using the abstract factory pattern, the client does not know which concrete objects - results - it gets from each of the internal factories, since it sees only the generic interfaces of their products. We would like to have a common interface for the client during bridge load testing or during the monitoring of special events. This is why it is very useful - this pattern separates the details of the implementation of a set of objects from their general use. As a result, it relies on the object composition - the result of load testing or results given by SHM systems is implemented in methods exposed in the factory interface. 
In bridge load testing it is a common practice that the customer is only interested whether the construction has met the formal rudiments. Usually the customer is interested in having functionality which allows quickly launching the most common tasks, while not hiding the complexity of the system.

One of the main BIM advantages is possibility to move risk to the digital phase. If this is done it is possible to simulate or use a different variant of the designs. The Memento pattern can be used to remember and make it available outside the internal state of the facility without disturbing the encapsulation. This allows restoring the saved state of the object. We can for instance, build a project of a monitoring system, in different versions, send them to the designer, get information in BCF format and thanks to the Memeto pattern, be able to choose one of them.

\section{Discussion and summary}

It is relatively easy to identify the customer's needs in providing information during the process of bridge load testing. At the stage of formulating tender requirements, they should be expressed in EIR and formulated precisely with help of IDM. However, it is important not to focus only on information requirements based on the IFC classes and subsets of these classes defined in selected MVDs.

The presented example of the interaction maps should be a good start on the way to the standardization of data exchange for the process of acceptance of a bridge realised with BIM technology. Thanks to this kind of a map, single, indivisible transactions as well as actors and their responsibilities are identified. Subsequently, it is possible to precisely define the information exchange sequences for a given transaction, link information requirements to them and set process terminators.

Information flow completeness, in particular between the phases of the project, is illustrated on the process map. Transitions between the swimming pools of thea ctors are information exchange points that should naturally meet the requirements defined in the interaction maps.

The authors support the position that it is a better idea to use the concept design patterns rather than the reference process. There are several reasons for this. The basic reason is that design patterns are more abstract. Therefore, their application for diversified projects will be easier. The second important reason is the protection of the intellectual property of individual companies. Design patterns are not a specific solution but they are only a template, therefore a detailed solution does not have to be disclosed by the company and yet it can implement the BIM process in accordance with the standard. The third important reason is the fact that this solution has come down so well in software engineering that some of the templates have been embedded in modern programming languages. Similarly, we expect that in the future BIM design patterns will be gradually built into IT systems supporting BIM processes. The beginning of this long road is to identify which design patterns can be imported into individual BIM processes. In this paper, we presented the possibility of using some of them to support the exchange of information for bridge load testing.

This paper was partially financed by AGH University of Science and Technology, Department of Engineering Surveying and Civil Engineering, as a part of statutory project No. 11.11.150.005.

This paper was partially financed by a subsidy for maintaining research potential and the financing of young scientists (University of Bielsko-Biała, Poland, Faculty of Materials, Civil and Environmental Engineering). 


\section{References}

1. 'ISO 29481-1:2016 - Building information models -- Information delivery manual -Part 1: Methodology and format'. [Online]. Available:

https://www.iso.org/standard/60553.html. [Accessed: 25-Apr-2018]

2. 'ISO 29481-2:2012 - Building information models -- Information delivery manual -Part 2: Interaction framework'. [Online]. Available:

https://www.iso.org/standard/55691.html. [Accessed: 25-Apr-2018]

3. R. See, J. Karlshoej, and D. Davis, 'An Integrated Process for Delivering IFC Based Data Exchange'. buildingSMART (2012)

4. J. Messner, C. Anumba, C. Dubler, S. Goodman, C. Kasprzak, and R. Kreider, 'BIM Project Execution Planning Guide’. The Computer Integrated Construction Research Program (CIC), Penn State University (2011)

5. J. Amann, A. Borrmann, T. Chipman, E. Lebegue, T. Liebich, and P. Scarponcini, 'IFC Alignment Project, Process Map and Use Cases'. BuildingSMART (2014)

6. G. Lee, Y. H. Park, and S. Ham, Adv. Eng. Inform. 27(4), 636-651, Oct. (2013)

7. 'PAS 1192-2:2013; Specification for information management for the capital/delivery phase of construction projects using building information modelling'. British Standards Institution (2013)

8. Á. Gigante-Barrera, D. Ruikar, M. Crunden, and K. Ruikar, J. Inf. Technol. Constr. ITcon, 22(5), 80-103, May (2017)

9. O. B. Berard and J. Karlshøj, J. Inf. Technol. Constr. 17, 77-87 (2013)

10. J. Steel, R. Drogemuller, and B. Toth, Softw. Syst. Model. 11(1), 99-109, Feb. (2012)

11. Giel Brittany and Issa Raja R. A., J. Manag. Eng. 32(1), p. 04015024, Jan. (2016)

12. S. Rizal and L. van Berlo, Archit. Eng. Des. Manag. 6(4), 254-263, Jan. (2010)

13. B. Succar, W. Sher, and A. Williams, Archit. Eng. Des. Manag. 8, 120-142, Mar. (2012)

14. J. L. G. Dietz, Enterprise Ontology: Theory and Methodology. Berlin Heidelberg: Springer-Verlag (2006)

15. E. Hjelseth, Archit. Eng. Des. Manag. 6(4), 279-287 (2010)

16. G. White and S. Cicmil, Int. J. Product. Perform. Manag. 6, 302-323, Mar. (2016)

17. J.-H. Woo, M. J. Clayton, R. E. Johnson, B. E. Flores, and C. Ellis, Autom. Constr. 13(2), 203-207, Mar. (2004)

18. G. Erich, R. Helm, R. Jahnson, and J. Vlissides, Inżynieria oprogrmowania. Wzorce projektowe. [Software engineering. Project patterns.], II. Warsaw: WNT, (2008) 